\title{
Synthesis of Hydroxy Sodalite from Coal Fly Ash for Biodiesel Production from Waste-Derived Maggot Oil
}

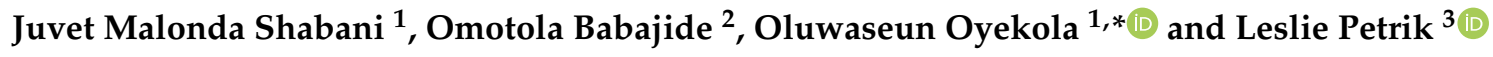 \\ 1 Department of Chemical Engineering, Cape Peninsula University of Technology, \\ Cape Town 7535, South Africa; juvetshabani@gmail.com \\ 2 Department of Mechanical Engineering, Cape Peninsula University of Technology, \\ Cape Town 7535, South Africa; omotola.babajide@gmail.com \\ 3 Environmental and Nano Science Research Group, University of Western Cape, \\ Cape Town 7535, South Africa; lpetrik@uwc.ac.za \\ * Correspondence: oyekolas@cput.ac.za; Tel.: +27-(0)-21-959-6799
}

Received: 3 September 2019; Accepted: 26 November 2019; Published: 11 December 2019

\begin{abstract}
Zeolites are aluminosilicate crystalline materials known for their unique characteristics, and have been prominent for nearly half a century due to their wide and important industrial applications. The production of zeolites, however, remains a challenge due to the high cost of commercial reagents conventionally used as feedstocks. In the current study, hydroxy sodalite (HS) zeolite samples were synthesised from coal fly ash feedstock by a direct hydrothermal synthesis method. The effects of hydrothermal crystallisation synthesis time on phase crystallinity, crystal size, and morphology of the formed HS were investigated. The prepared samples were characterised using XRD, SEM, EDS and FT-IR techniques. The XRD results of the samples prepared with varying synthesis times confirmed the formation of HS from low to high phase purity and crystallinity from 11 to over $98 \%$. The SEM results reflected gradual variation in crystal morphology, of which highly crystalline HS samples were associated with hexagonal-cubic and cubic-platelet crystals. The FTIR, depicting zeolite characteristics of $\mathrm{T}-\mathrm{O}$ and $\mathrm{T}-\mathrm{O}-\mathrm{T}$ stretching vibrations in the molecular framework, further confirmed the formation of HS zeolites for samples obtained above the 24-h synthesis time. These zeolite samples were then evaluated for their catalytic activities in the conversion of maggot oil to biodiesel. The application of the various hydroxy sodalite samples for the transesterification of maggot oil yielded up to $84.10 \%$ biodiesel (FAME) with physicochemical properties that were in compliance with the biodiesel specification standards. This study investigated the novel use of a coal fly ash-derived, heterogeneous HS catalyst in biodiesel production from maggot oil, and indicates its potential to enhance biodiesel yield and quality upon process optimisation tests.
\end{abstract}

Keywords: hydroxy sodalite; coal fly ash; zeolites; biodiesel; maggot oil

\section{Introduction}

Zeolites are aluminosilicate materials that have been known for over 250 years; they occur naturally, but have been synthetically produced on a large-scale due to their wide use in various applications [1]. Zeolites have different mineral phase structures; thus, their synthesis pathway should be tailored to obtain a particular phase for a given application. Molecular sieving, shape selectivity, sorption, and ion-exchange capacity are some of the unique characteristics of zeolites that make their application valuable in important industrial processes [2-4]. By the nature of their synthetic pathways, the conventional production of zeolites in large quantities is a challenge associated with the use of commercial compounds as feedstocks, which results in the high cost of zeolite products $[5,6]$. 
Although zeolites can be prepared synthetically from various aluminosilicate sources, the above concern motivated this research to explore the use of coal fly ash as an alternative, potentially cheaper and highly-abundant feedstock source, for the preparation of hydroxy sodalite zeolite as a candidate catalyst in biodiesel production. Coal fly ash (CFA) is a solid waste residue resulting from coal burning at power stations, of which over $30 \mathrm{Mt}$ is generated yearly in South Africa (and $800 \mathrm{Mt}$ globally). About $5 \%$ is recycled for valuable applications [3,7]. The remainder represents a major pollutant to the environment, and has caused disposal challenges on terrestrial and aquatic ecosystems [8]. Coal fly ash has the potential for reuse as an additive to cement and concrete manufacturing in the construction industry, for soil amelioration in agriculture, as fill material for low lying areas, and in the synthesis of valuable industrial catalysts [3,8]. Other than potentially reducing the cost of zeolites to about one-fifth of that of the commercial zeolite, coal fly ash inherently contains glassy silicon and aluminium in high proportion, such that the feedstock may not necessarily have to come from multiple sources for zeolite synthesis, as compared to zeolite produced from commercial sources [9]. Due to the abundant and continual generation of coal fly ash, it is envisaged that the material is a readily-available source (alumina-silica material) of the precursors required to produce zeolites. Coal fly ash, by virtue of its fine particulate nature, implies a low-energy demand, as it does not require crushing and high-temperature calcination before zeolite synthesis, in comparison to various conventional silica sources [3].

The hydrothermal method is the principal and most commonly-used method for the synthesis of zeolites from coal fly ash [2]. This method involves the dissolution of the aluminosilicate glass contained in CFA in an alkaline solution, which is subsequently converted to the crystalline zeolite phase [10]. Hydroxy sodalite is a hydrophilic zeolite that possesses sodalite cages which are connected in such a way that they enclose small Åsize pores [11]. The pores consequently make the application of the material suitable and effective in molecular separation processes and various industrial processes [2]. The small pore apertures imply a large exposed external surface area of HS as a crystalline material, which, when synthesised hydrothermally with alkaline reagents, provides a solid base medium. This property makes HS a suitable catalytic medium, and consequently a solid base catalyst for biodiesel production [9]. As a base catalyst, it is assumed that the use of HS in biodiesel production will achieve high catalytic activity as conventional base homogenous catalysts, the latter being predominant in industrial large-scale production [12]. Moreover, the focus on HS as a solid heterogeneous base catalyst in biodiesel production is gaining much interest due to the challenges of washing, saponification, high water consumption and catalyst separation incurred by the use of the conventional homogenous catalysts $[13,14]$.

Most review papers to date have reported on the synthesis of zeolites (HS) from commercial reagents $[9,15]$. Although the use of commercial reagents seems to have shortened the synthesis route, their high cost is still reported to increase the overall cost of the final zeolite products [5,9]. Although zeolites have been successfully synthesised from coal fly ash, a challenge remains in obtaining high-quality (pure phase and high crystalline) zeolites [16], which is associated with the synthesis conditions and costs [15,17-19]. Zeolites as heterogeneous catalysts are associated with energy-intensive synthesis routes, which are analogous to high synthesis costs. This study was aimed at resource recovery from coal fly ash, to minimise zeolite synthesis costs by investigating the catalyst synthesis under varying conditions for their application in biodiesel production from maggot oil.

Maggot oil, the feedstock of interest in this study, is a waste-derived fat, extruded from the maggots of black soldier fly (BSF) insects that feed on food wastes and convert the wastes into fat. The oil emerges with large availability and is a by-product of the world's first waste-to-fly factory (AgriProtein) located in Cape Town (South Africa). The oil is applied exclusively for low market value products (animal feed) to date. It was found in previous studies to possess suitable feedstock characteristics for biodiesel production $[20,21]$. Consequently, literature provides a benchmark for this study to convert the oil into biodiesel, using a HS heterogeneous catalyst. To date, this is the only study in which a coal fly ash-derived, heterogeneous catalyst of HS zeolite form, is synthesised for biodiesel production. The synthesis of HS zeolite is carried out under varying conditions and investigated for application in the 
transesterification of maggot oil. According to the few existing studies in the literature, maggot oil (biologically known as a lipid of the Hermetia illucens black soldier fly) has been mainly assessed for its fatty acid composition [21] and biodiesel production feasibility using conventional homogenous sodium hydroxide and a sulphuric acid catalyst [20,22]. This study, therefore, focused on the use of the oil for biodiesel preparation using various synthesised heterogeneous HS (zeolites) catalysts. This study further assesses the physicochemical qualities of derivative FAME (biodiesel).

\section{Results and Discussion}

\subsection{Effect of Hydrothermal Synthesis Time on HS Formation}

\subsubsection{XRD Results}

The samples synthesised after 48-h synthesis time showed an almost completely pure phase of HS. These samples were constituted entirely of high HS phase purity and did not contain mixed phases of other crystalline materials (Figure 1).

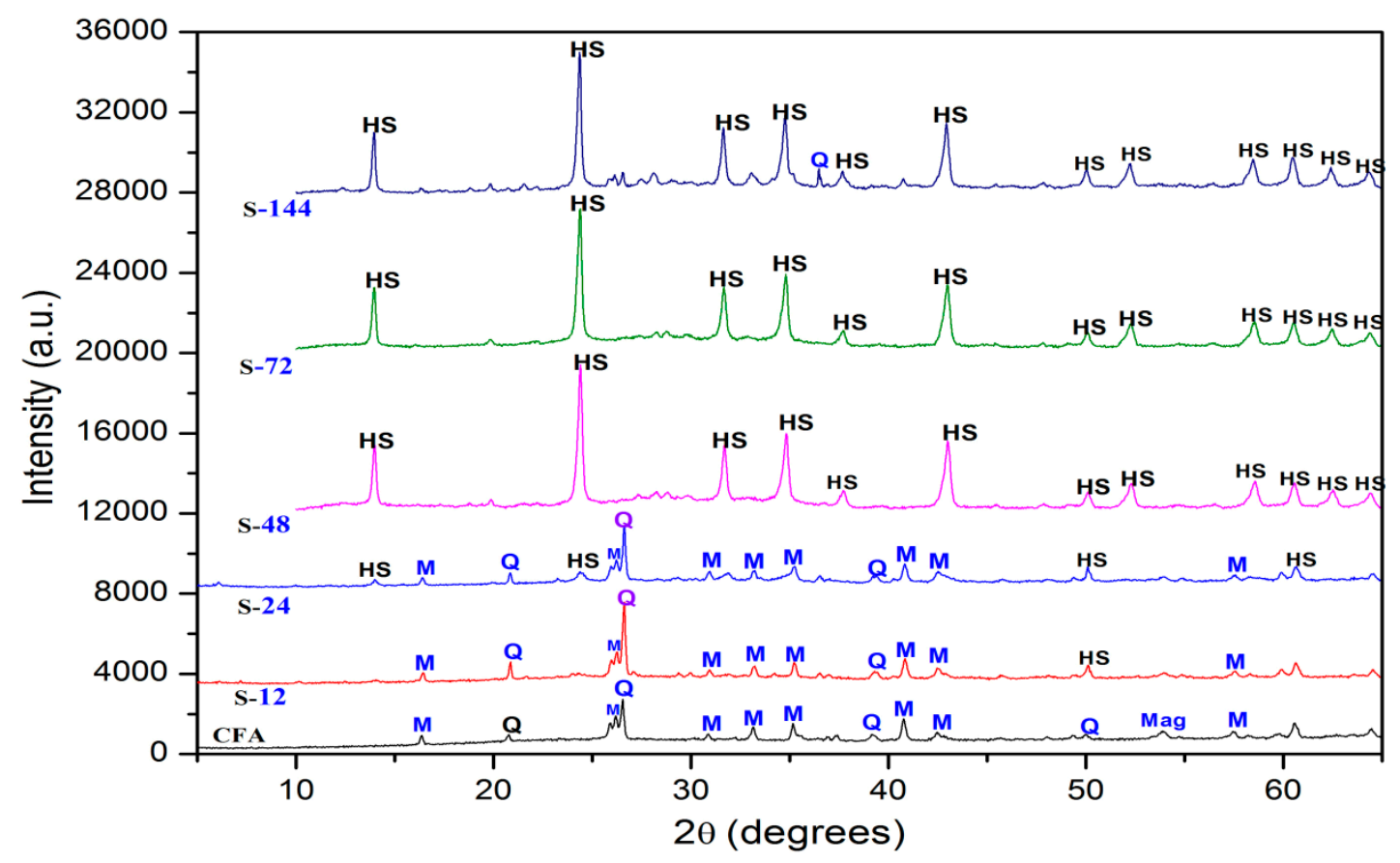

Figure 1. XRD patterns displaying the effect of synthesis time on HS formation.

The above, therefore, indicates that all the mullite $(\mathrm{M})$ and quartz $(\mathrm{Q})$ phases in coal fly ash (CFA) were converted almost fully into the zeolite phase during the ageing and hydrothermal synthesis steps. This demonstrates that ageing at $70{ }^{\circ} \mathrm{C}$ for $1.5 \mathrm{~h}$ could substitute the high temperature fusion step that is conventionally employed $[5,17,23]$. The effect of synthesis time was evaluated over different periods $(12,24,72$ and $144 \mathrm{~h})$. Both the S-12 and S-24 samples synthesised hydrothermally for less than $48 \mathrm{~h}$ showed almost no crystalline phases of HS (Figure 1). Their XRD patterns displayed rather significant amounts of unconverted and mixed amorphous phases of mullite (M) and quarts (Q). All samples synthesised above $48 \mathrm{~h}$ displayed XRD patterns exhibiting the formation of the hydroxy sodalite (HS) phase. The XRD pattern of the sample synthesised after $72 \mathrm{~h}$ (S-72) showed high phase purity. In other words, a minimum synthesis time of $48 \mathrm{~h}$ at the adopted fixed temperature $\left(140{ }^{\circ} \mathrm{C}\right)$ was necessary for the synthesis of HS from coal fly ash by the direct method. This observation suggests that no synthesis time below $48 \mathrm{~h}$ under the given, fixed conditions would be favourable for the synthesis of high phase HS. This finding supports the report by Musyoka et al. [16] favouring the selection of a 48-h synthesis period. 
Low HS phase crystallinities of $11 \%$ and $18 \%$ characterised the samples synthesised after 12 and $24 \mathrm{~h}$ respectively (Table 1 ). By an increase in synthesis time to 48,72 and $144 \mathrm{~h}$, HS phase crystallinity (as per reference sample) was enhanced to $98 \%, 100 \%$ and $85 \%$ respectively.

Table 1. Effect of hydrothermal synthesis time on phase crystallinity and crystal size of synthesised products at $140{ }^{\circ} \mathrm{C}$.

\begin{tabular}{|c|c|c|c|}
\hline Sample & Synthesis Time (Hour) & HS Crystallinity (\%) ${ }^{a}$ & Crystal Size (nm) \\
\hline S-12 & 12 & 11 & 43.6 \\
\hline S-24 & 24 & 18 & 21.1 \\
\hline S- 48 & 48 & 98 & 32.4 \\
\hline $\mathrm{S}-72^{\mathrm{b}}$ & 72 & 100 & 31.9 \\
\hline S-144 & 144 & 85 & 38.1 \\
\hline
\end{tabular}

${ }^{a}$ Relative crystallinity. ${ }^{b}$ Reference sample for crystallinity measurement.

\subsubsection{Effect of Hydrothermal Synthesis Time on Catalyst Morphology}

Coal fly ash, the starting material used for the synthesis of HS zeolite, was found to consist entirely of spherical crystals. The produced HS samples, on the other hand, were found to consist of a variety of crystal morphologies, with peculiarities or uniformity observed according to changes in synthesis time. As shown in Table 1, the S-12, exhibited a very low HS phase crystallinity of $11 \%$; this sample was morphologically (Figure 2b) constituted of rough-surfaced, spheroidal crystals.

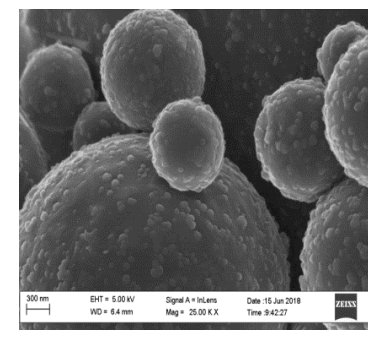

(a)

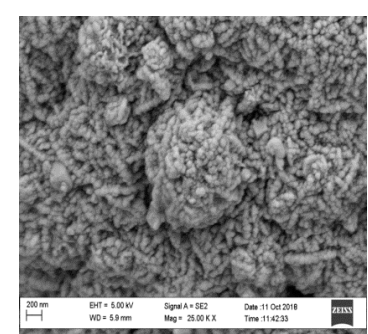

(c)

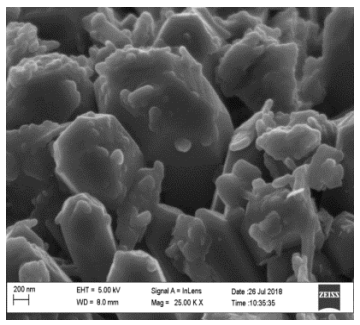

(e)

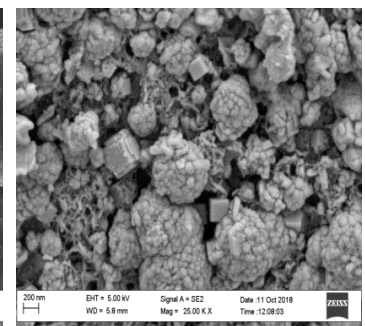

(b)

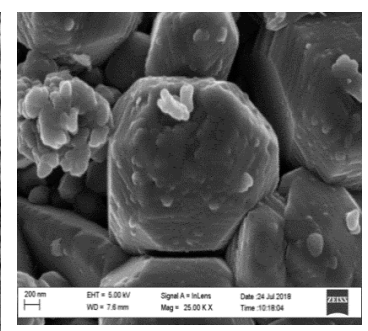

(d)

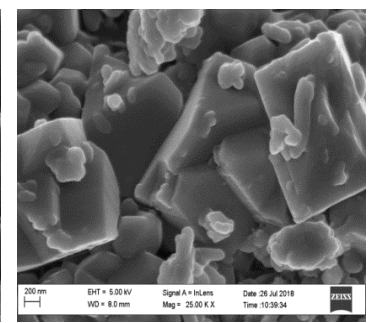

(f)

Figure 2. SEM micrographs: (a) Arnot fly ash; (b) S-12 (HS catalyst sample synthesised at 12-h hydrothermal synthesis time); (c) S-24 (HS catalyst sample synthesised at 24-h hydrothermal synthesis time); (d) S-48 (48-h hydrothermal synthesis time HS catalyst); (e) S-72 (72-h); and (f) S-144 (144-h hydrothermal synthesis time HS catalyst). 
The above comparison also attests to the insufficient synthesis time for the conversion of amorphous phases of coal fly ash into HS zeolite HS. By increasing the synthesis time to $24 \mathrm{~h}$, the morphology of the resultant S-24 sample, as presented in Figure 2c, evolved into agglomerated thread, ball-like crystals. The hierarchical ball-like morphology is commonly associated with HS zeolite [9]. In spite of the above, the sample in question exhibited a very low HS crystalline phase (18\%). It is therefore evident that the morphological representation of HS (or any other zeolite type) through SEM data alone is not always the yardstick reflection of the particular phase identity. A similar observation was reported by Nanganoa et al. [23]. A further increase in synthesis time to $48 \mathrm{~h}$ resulted in a uniform and more defined morphology of smooth-surfaced HS crystals in hexagonal-cubic shapes (Figure 2d). With a 72-h hydrothermal synthesis time, a uniform S-72 sample of a morphology comparable to that of S-48 was observed (Figure 2e). In contrast to smooth-surface crystals, the S-72 comprised rough-surfaced, hexagonal-cubic crystals. After a 144-h synthesis time, a hierarchical, cubic-platelet morphology appeared, as depicted in Figure $2 \mathrm{f}$.

\subsection{Elemental Composition and Si/Al Ratio of the Synthesised Catalysts}

All the synthesised samples were found to consist of similar elemental compositions (Table 2). The main components identified were $\mathrm{Si}-\mathrm{Al}-\mathrm{O}$ (oxides of silicon and aluminium) and oxides of metallic elements. These reflect the composition of a typical zeolite, as reported in literature [10]. The range of the $\mathrm{Si} / \mathrm{Al}$ ratio obtained for the prepared samples was between 0.8 and 1.4. This corresponds to that of HS zeolite, as reported in literature [11,23]. Although the S-24 sample exhibited the $\mathrm{Si} / \mathrm{Al}$ ratio closest to that of typical HS zeolite, this sample, as earlier reported in Table 1 and Figure 1, exhibited a low phase purity and low crystallinity of HS. Nonetheless, the relative increase in the Si/Al ratio to 1.2 (as in Table 2), by virtue of the increased synthesis time, was found to be associated with the enhanced morphology of zeolites. Moreover, a dominant direct correlation was observed between the increased $\mathrm{Si} / \mathrm{Al}$ ratio and the increased HS phase crystallinity (Table 1). 
Table 2. Effect of hydrothermal synthesis time on phase crystallinity and crystal size of synthesised products at $140{ }^{\circ} \mathrm{C}$

\begin{tabular}{|c|c|c|c|c|c|c|c|c|c|c|c|c|c|}
\hline \multirow{2}{*}{ Sample } & \multicolumn{13}{|c|}{ Element (Atomic, w/w\%) } \\
\hline & $\mathbf{O}$ & Al & $\mathrm{Si}$ & $\mathrm{Na}$ & Mg & K & $\mathrm{Ca}$ & Ti & $\mathrm{Fe}$ & $\mathbf{P}$ & Total & Si/Al Ratio & $\mathrm{Na}$ /Al Ratio \\
\hline CFA & 65.15 & 11.23 & 14.86 & - & 1.54 & 0.23 & 4.32 & 0.30 & 1.13 & 1.25 & 100.0 & 1.32 & - \\
\hline S-12 & 58.63 & 17.08 & 17.49 & 3.04 & 0.58 & 0.37 & 1.30 & 0.90 & 0.62 & - & 100.0 & 1.02 & 0.18 \\
\hline S-24 & 59.35 & 16.50 & 13.33 & 4.89 & 0.99 & 0.38 & 2.69 & 0.78 & 1.09 & - & 100.0 & 0.81 & 0.30 \\
\hline S- 48 & 45.09 & 14.32 & 19.5 & 14.62 & 0.65 & - & 3.57 & 0.93 & 1.33 & - & 100.0 & 1.36 & 1.02 \\
\hline S-72 & 44.77 & 13.97 & 19.07 & 15.24 & 0.96 & - & 3.78 & 0.79 & 1.43 & - & 100.0 & 1.37 & 1.09 \\
\hline S-144 & 43.47 & 13.76 & 17.42 & 20.67 & - & - & 2.16 & 1.23 & 1.29 & - & 100.0 & 1.27 & 1.50 \\
\hline
\end{tabular}




\subsection{Fourier Transform Infrared (FTIR) of Synthesised Samples}

The FTIR analyses shown in Figure 3 demonstrate the structural configuration of the synthesised samples from coal fly ash starting material (a). The quartz (Q) bands detected in CFA (a) at $1095 \mathrm{~cm}^{-1}$, disappeared after the synthesis steps and shifted towards $975 \mathrm{~cm}^{-1}$ and lower frequencies in the product, indicating successful conversion of the coal fly ash content to zeolites. The band characteristic of the synthesised samples between 420 and $2000 \mathrm{~cm}^{-1}$, including the bulk of vibrational modes observed between 450 and $750 \mathrm{~cm}^{-1}$, represents the characteristics of a typical zeolite structure [15]. As an exception to the above, the samples synthesised below 48-h synthesis time (i.e., 12, $24 \mathrm{~h}$ ), displayed very weak characteristic bands of the zeolite structure (Figure 3).

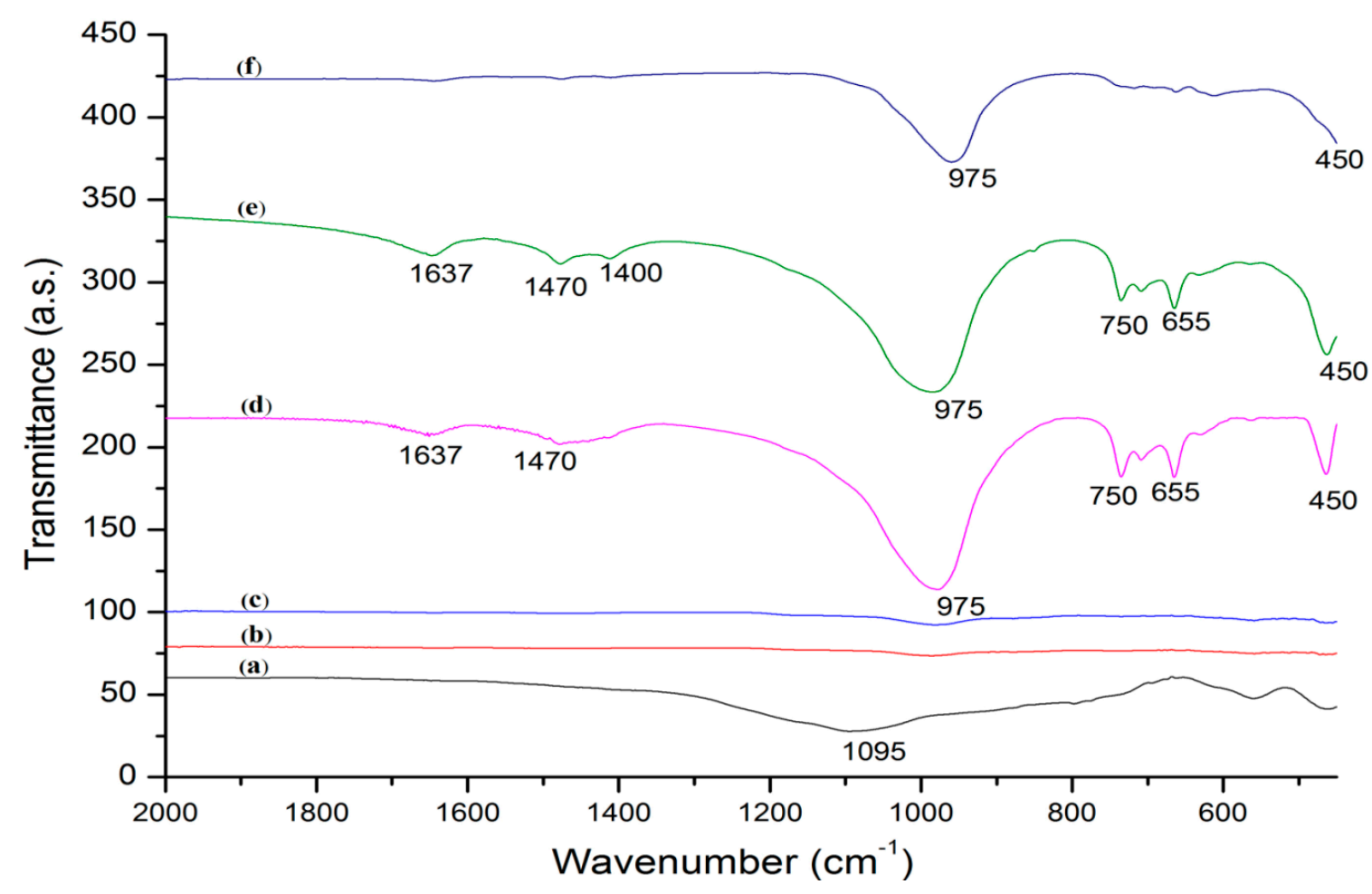

Figure 3. FTIR spectra of synthesised HS at various conditions of direct hydrothermal synthesis time: (a) CFA; (b) S-12; (c) S-24; (d) S-48; (e) S-72; and (f) S-144.

HS (Zeolite) vibrational modes began to emerge with an increase in the hydrothermal synthesis time, i.e., $48 \mathrm{~h}$, with an internal bending vibration of $\mathrm{T}-\mathrm{O}$ ( $\mathrm{T}-\mathrm{Si}$ or $\mathrm{Al}$ ) partially detected between 450 and $500 \mathrm{~cm}^{-1}$. This was followed by consecutive bands detected at 655 and $750 \mathrm{~cm}^{-1}$, corresponding to double ring vibrations of tetrahedral $\mathrm{Si}-\mathrm{O}$ and $\mathrm{Si}-\mathrm{O}-\mathrm{Al}$ respectively [23].

Broad transmittance bands of symmetric stretching of $\mathrm{T}-\mathrm{O}-\mathrm{T}$, associated with external vibrations or linkages between $\mathrm{Si}-\mathrm{O}$ and $\mathrm{Al}-\mathrm{O}$ tetrahedral units, were further detected in the region between 905 and $1100 \mathrm{~cm}^{-1}$. This band also demonstrates a balance in the number of $\mathrm{Si}-\mathrm{O}$ tetrahedral and $\mathrm{Al}-\mathrm{O}$ tetrahedral units formed. Asymmetric stretching bands of $\mathrm{T}-\mathrm{O}-\mathrm{T}$, mainly associated with vibrations of $\mathrm{Si}-\mathrm{O}$ tetrahedral units, were exclusively detected in zeolitic sample of S-48 and S-72 in the region between 1350 and $1562 \mathrm{~cm}^{-1}$. This band for S-72 contained an additional internal vibration of tetrahedral $\mathrm{Si}-\mathrm{O}$ at $1400 \mathrm{~cm}^{-1}$, indicating the presence of relatively more $\mathrm{Si}-\mathrm{O}$ tetrahedral units in this sample. Consequently, the S-72 sample, as reported in the EDS analyses shown in Table 2, exhibits the highest $\mathrm{Si} / \mathrm{Al}$ ratio. A narrow symmetric stretching band was further detected exclusively in sample S-48 and S-72 at $1637 \mathrm{~cm}^{-1}$. This was mostly associated with the formation of the Si-O tetrahedral unit. Beyond the above band, the region further above $1637 \mathrm{~cm}^{-1}$ in all samples synthesised above $24 \mathrm{~h}$ was attributed to water molecules attached to sodalite. With an increase in hydrothermal synthesis 
time, as consecutively indicated (c-d-e-f) in Figure 3, tetrahedral T-O-T frameworks evolved, with the characteristic zeolite structures being optimally exhibited after 48- and 72-h synthesis time.

\subsection{Transesterification of Maggot Oil}

The maggot oil from Agriprotein (Ltd) is metabolically derived from the maggots of black soldier flies (BSF) upon feeding and growing on food wastes. The highly saturated oil appears as fat at room temperature [24]. It was found to consist of high free fatty acid (FFA) concentration $(7.2 \mathrm{mg} \mathrm{of} \mathrm{KOH} / \mathrm{g}$ oil) (Table 3). The high FFA content would have impaired the application of a homogeneous catalyst for the transesterification process. Alternatively, a preliminary esterification process would have been required. The properties of the oil, including their fatty acid profiles, as determined in this study, are shown in Table 3.

Table 3. Physicochemical properties of maggot oil.

\begin{tabular}{|c|c|}
\hline \multicolumn{2}{|c|}{ Maggot Oil Properties } \\
\hline Acid value (mg KOH/g) & 7.2 \\
\hline Saponification value $(\mathrm{mg} \mathrm{KOH} / \mathrm{g})$ & 176.43 \\
\hline Iodine value ( $\mathrm{g}$ of $I_{2} / 100 \mathrm{~g}$ ) & 44.27 \\
\hline Density at $40{ }^{\circ} \mathrm{C}(\mathrm{g} / \mathrm{mL})$ & 0.883 \\
\hline Kinematics viscosity at $40^{\circ} \mathrm{C}\left(\mathrm{mm}^{2} / \mathrm{s}\right)$ & 43.16 \\
\hline \multicolumn{2}{|l|}{ Fatty acid (wt.\%) } \\
\hline $\mathrm{C} 12: 0$ & 37.14 \\
\hline C14:0 & 7.1 \\
\hline C16:0 & 23.84 \\
\hline $\mathrm{C} 16: 1$ & 3.16 \\
\hline C18:0 & 2.52 \\
\hline C18:1 & 17.81 \\
\hline $\mathrm{C} 18: 2$ & 8.44 \\
\hline C18:3 & - \\
\hline C20:0 & - \\
\hline
\end{tabular}

All the coal fly ash-based hydroxy sodalite samples, as identified by XRD and FTIR, revealed a potential activity in the transesterification of maggot oil to biodiesel, as reported in Figure 4. An increase in the catalyst synthesis time of S-24, S- 48, S-72 and S- 144 was overall correlated with an increase in the biodiesel yield of $73.10,86.00,81.45,84.10$ and $80.60 \%$ respectively. The observed increase in the biodiesel yield was associated with increased HS phase crystallinity (Table 1) and defined morphology (Figure 2). Increased crystallinity, as associated with large crystal size of samples (Table 1), offers a relatively high diffusion constraint on reacting molecules around crystal surfaces, and consequent low yield of biodiesel by catalysts S-12 and $\geq S-48$ as compared to S-24. Moreover, the increase in biodiesel yield is associated with catalysts characterised by more distinct pores, accounted for on the basis of XRD peaks below $15^{\circ} 2 \theta$ (Figure 1) and associated with well-defined and increasing crystal sizes. 


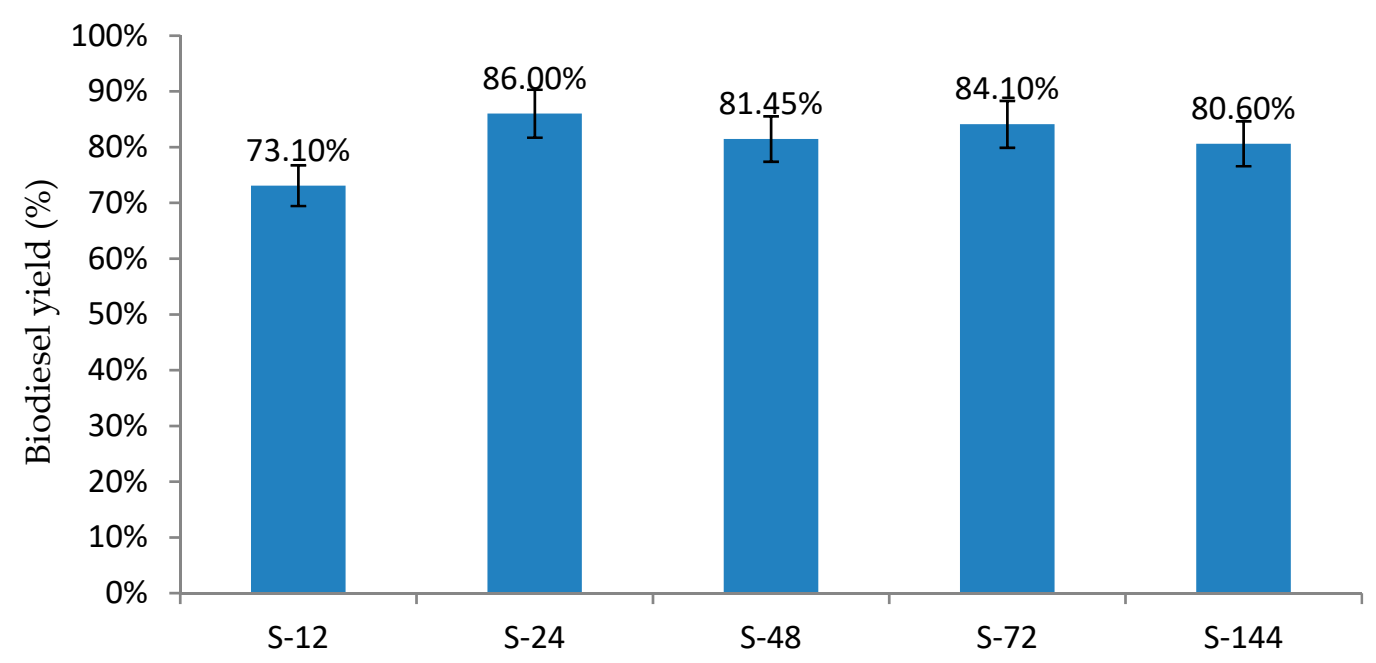

Figure 4. Catalytic activity of synthesised samples as a function of synthesis time on FAME yield in biodiesel production from maggot oil under transesterification conditions [1.5-h reaction at $60{ }^{\circ} \mathrm{C}, 15: 1$ methanol-oil ratio and $1.5 \%$ catalyst $\mathrm{w} / \mathrm{w}$ of oil].

Crystal size proved to have a greater impact than the long-range crystallinity in defining the yield of biodiesel. Although the S-24 sample resulted in crystallite without a long-range order, that does not mean that the HS mineral phase was not formed (Figure 1). The high biodiesel yield obtained over the S-144 catalyst may be attributed to the higher $\mathrm{Na} / \mathrm{Al}$ ratio exhibited by the sample, as well as the high $\mathrm{Si} / \mathrm{Al}$ ratio thereof (Table 2). The latter serves as an indication of high degree of acidity or large amount of Bronsted acidic sites on the external surface of the S-144 catalyst sample [25]. Catalyst acidity was, therefore, in terms of $\mathrm{Si} / \mathrm{Al}$ ratio, another critical factor in determining the yield of biodiesel.

\section{The Quality of Biodiesel Produced}

The quality of each biodiesel product obtained was characterised vis-à-vis the catalyst synthesis time and the corresponding properties. The property specifications of each biodiesel produced correlate to the EN1421 international standards (Table 4). The biodiesel obtained from the shorter synthesis time-based catalysts of S-12 and S-24 partially displayed the required standard specifications, with the latter adhering only in terms of viscosity $\left(4.90 \mathrm{~mm} / \mathrm{s}^{2}\right)$, while both slightly exceeded the specifications in terms of other properties, such as acid value $(0.56$ and $0.60 \mathrm{mg} \mathrm{KOH} / \mathrm{g}$ oil $)$ and density $(0.975$ and $0.905 \mathrm{~g} / \mathrm{cm}^{3}$ ). It can therefore be deduced that the almost entirely non-conforming biodiesel quality obtained over the S-12 and S-24 catalyst were as a result of the low shape-selective surface property and low diffusion constraint of these samples, while the effective biodiesel yield obtained by the S-24 catalyst was attributed to its relatively small crystal size. 
Table 4. Physicochemical properties of maggot oil.

\begin{tabular}{|c|c|c|c|c|c|c|}
\hline \multirow[t]{2}{*}{ Biodiesel Properties } & \multicolumn{5}{|c|}{ Obtained from Current Study for Respective SYNTHESISED CAtalysts } & \multirow{2}{*}{$\begin{array}{c}\text { B-STANDARD }^{\mathrm{a}} \\
\text { ENS }^{\mathrm{b}} / \mathrm{ASTM}^{\mathrm{c}}\end{array}$} \\
\hline & HS-12 & S-24 & S-48 & S-72 & S-144 & \\
\hline \multirow[t]{2}{*}{ Acid value $(\mathrm{mg} \mathrm{KOH} / \mathrm{g})$} & 0.56 & 0.60 & 0.53 & 0.49 & 0.47 & $0.5-0.8 \mathrm{Max}$ \\
\hline & - & - & - & - & 148.59 & - \\
\hline \multicolumn{7}{|l|}{ Saponification value $(\mathrm{mg} \mathrm{KOH} / \mathrm{g})$} \\
\hline \multirow[t]{2}{*}{ Ester content ${ }^{\mathrm{d}}(\% \mathrm{~m} / \mathrm{m})$} & 35.83 & 42.49 & 59.56 & 62.64 & 97.50 & 96.5 \\
\hline & - & - & 59.02 & 56.86 & 50.17 & 130 \\
\hline \multicolumn{7}{|l|}{ Iodine value ( $\mathrm{g}$ of $I_{2} / 100 \mathrm{~g}$ ) } \\
\hline \multirow[t]{2}{*}{ Density at $40{ }^{\circ} \mathrm{C}(\mathrm{g} / \mathrm{mL})$} & 0.975 & 0.905 & 0.931 & 0.897 & 0.907 & $0.86-0.90$ \\
\hline & 6.18 & 4.90 & 5.73 & 5.70 & 5.73 & $3.5-5.0$ \\
\hline \multirow{2}{*}{ Kinematics viscosity at $40{ }^{\circ} \mathrm{C}\left(\mathrm{mm}^{2} / \mathrm{s}\right)$} & & & & & & $1.9-6.0$ \\
\hline & 1.4450 & 1.4443 & 1.4454 & 1.4450 & 1.4461 & 1.479 \\
\hline
\end{tabular}

a Biodiesel Standard Specifications; ${ }^{\mathrm{b}}$ ENS14214 and ${ }^{\mathrm{c}}$ ASTMD675 (European and American). ${ }^{\mathrm{d}}$ Obtained from GC characterisation FAME data of respective biodiesel products. ${ }^{\mathrm{e}}$ Figures reported in four significant figures to enhance accuracy or minimise error of comparison. 
As with the increase in the yield of biodiesel, a higher quality biodiesel product was associated with catalysts generated at higher synthesis times, starting from the 48-h synthesised catalyst (S-48) that yielded a slightly higher quality biodiesel as compared to the S-24 catalyst. Further, an increase in HS crystallinity, resulting from an increase in the catalyst synthesis time to $\geq 72 \mathrm{~h}$, is associated with improved biodiesel properties such as acid value, density and enhanced ester content. Acid values of both S-72 and S-144 were below the maximum $0.5 \mathrm{KOH} / \mathrm{g}$ oil; comparably higher iodine values (56.86 and $50.17 \mathrm{~g}$ of $\mathrm{I}_{2} / 100 \mathrm{~g}$ oil respectively) are indicative of highly reactive biodiesel products. In contrast to the other obtained biodiesel properties, the biodiesel ester content obtained using the first four catalysts did not comply with the EN standard specifications, except when the S-144 catalyst was employed. The S-72 catalyst exhibited an ester content (62.64\%) below the required standard specification and the S-144 sample yielded up to $97.5 \%$ ester content (Table 4). This observation suggests that increased HS crystallinity to an optimum of $85 \%$ enhanced the catalyst basic site strength (infused by the high sodium concentration or high $\mathrm{Na} / \mathrm{Al}$ ratio exhibited in catalyst sample; see Table 2). Further, increased crystal size of $38.1 \mathrm{~nm}$ and defined crystal morphology of S-144 (Figure 2), promoted a relatively high diffusion constraints, large surface contact and longer contact period of reacting molecules over the catalyst. The high shape-selective catalytic surface environment also played a crucial role in the synthesis of an effective catalyst for a considerable biodiesel quality.

\section{Materials and Methods}

\subsection{Materials}

Coal fly ash (CFA) was obtained from a coal-fired power station located in the Mpumalanga region of South Africa. It was stored in an air-tight container and kept under dark conditions. Sodium hydroxide $(\mathrm{NaOH})$ of $98 \%$ grade was purchased from Kimix chemicals, and sodium aluminate (50-56\% $\mathrm{Al}_{2} \mathrm{O}_{3}$ and $40-45 \%$ ) was obtained from from Sigma Aldrich. The in-house deionised water required in the synthesis of zeolite was obtained using laboratory water distillation equipment. Maggot oil, being the biodiesel feedstock of choice in this study, was obtained from the AgriProtein Company, located in Cape Town, South Africa.

\subsection{Catalyst Preparation}

A $5 \mathrm{M}$ solution of $\mathrm{NaOH}$ was prepared using $50 \mathrm{~mL}$ of deionised water; this was mixed with $10 \mathrm{~g}$ of coal fly ash to achieve a 1:1.2 mass ratio of CFA to $\mathrm{NaOH}$. The solution was then transferred into a $250 \mathrm{~mL}$ polypropylene bottle and subjected to ageing under stirring $\left(800 \mathrm{rpm}, 70{ }^{\circ} \mathrm{C}\right.$, and $1.5 \mathrm{~h}$ ). The resultant aged gel solution was then transferred into a $100 \mathrm{~mL}$, Teflon lined, stainless-steel autoclave, which was placed in an oven for hydrothermal crystallisation at $140{ }^{\circ} \mathrm{C}$ for $48 \mathrm{~h}$. The initial conditions of the synthesis time were adopted from Musyoka's [16] work. The resultant product was then cooled to room temperature, filtered and thoroughly washed with deionised water until a filtrate with a $\mathrm{pH}$ of about 10 was obtained. The product solid residue was dried in an oven at $70^{\circ} \mathrm{C}$ for $24 \mathrm{~h}$. The dried sample was weighed, stored and a certain amount was characterised. Various batches were made using the above procedure which was repeated by varying the hydrothermal synthesis time $(12,24,72$ and $144 \mathrm{~h})$. Product samples were named in accordance with the various synthesis times i.e., S-12, S-24, S-48, S-72 and S-144 respectively.

\subsection{Catalyst Characterisation}

All the produced coal fly ash-derived HS samples were characterised using X-Ray diffraction (XRD), Fourier Transform Infrared (FTIR) and Energy-dispersive spectroscopy (EDS) coupled with Scanning Electron Microscopy (SEM). The XRD analysis was conducted to determine the mineral phases and crystallinity of the samples, using a Bruker AXS, equipped with LynxEye detector and operating with $\mathrm{Cu}-\mathrm{K} \alpha$ radiation $(\lambda \mathrm{K} \alpha 1=1.5406 \AA)$ at $40 \mathrm{kV}$ and $40 \mathrm{~mA}$. The raw XRD data of the characterised samples were afterwards interpreted with the aid of the Origin analysis software 
(version 8.5). The identification of the HS phase of interest was conducted using the standard and simulated XRD material data of sodalite, obtained from the database of the International Zeolite Association (IZA) [26]. The phase crystallinity of the catalyst samples was determined using the sum of the peak areas of the crystalline phase of HS over the sum of peak areas of that in the pattern of the reference sample (Equation (1)). The selection of the reference sample was based on the highest sum of the areas of HS peaks identified, of which the crystallinity was assigned as $100 \%$.

$$
\% \text { Crystallinity }=\frac{\text { Sum of areas of the crystalline phase of interest }(\mathrm{CPI})}{\text { Sum of the area of CPI in the reference sample }} \times 100
$$

The average crystal size of the produced samples was determined using the Scherrer equation depicted in Equation (2).

$$
\mathrm{B}(2 \theta)=\frac{\mathrm{K} \lambda}{\mathrm{LCos} \theta}
$$

where $\mathrm{L}$ is the average crystallite size of interest in the sample in $\mathrm{nm}, \mathrm{B}$ is the average peak Width or Full Width at Half maximum (FWHM) and $\theta$ is the diffraction angle in degree (converted to Radians).

The SEM analysis, coupled with EDS, was performed by mounting the powder of each sample on a stub coated with carbon conductive tape. Over this, the SEM-EDS (Data) mapping spectra were generated at three different regions of each sample using a high magnification ZeiSS Gemini Auriga instrument (equipped with a CDU-lad detector operating at $25 \mathrm{kV}$ ). The resultant data were used to determine the crystal morphology and elemental composition of each synthesised sample. The data of the EDS elemental composition were obtained as the average detected at each spectrum region and normalised without accounting for carbon content derived from coating. The FTIR characterisation, conducted using a Perkin Elmer 100 FT-IR, was used to determine the structural configuration of the samples. The latter was recorded to be in the range of between 450 and $2000 \mathrm{~cm}^{-1}$.

\subsection{Biodiesel Production and Characterisation}

The synthesised Na-form HS samples were then tested for transesterification of maggot oil. The reaction was conducted in a $250 \mathrm{~mL}$, three-neck, round bottom flask equipped with a reflux condenser, over a laboratory hotplate. An amount of $20 \mathrm{~g}$ of oil was transferred into a $250 \mathrm{~mL}$, two-neck, round bottom flask and preheated. To this the mixture of catalyst and methanol, equivalent to a catalyst weight of $1.5 \%$ to oil and a 15:1 mole ratio of methanol to oil, was added and reacted for transesterification at $60^{\circ} \mathrm{C}$ for $1.5 \mathrm{~h}$. The resultant product mixture containing the biodiesel (FAME) produced was centrifuged for layer and catalyst separation. The mixture was then transferred into the separation flask, in which it was washed with hot water until clear water was obtained. The washed biodiesel layer was then dried at $65^{\circ} \mathrm{C}$ using anhydrous sodium sulphate. The layer was allowed to cool, weighed and stored prior to characterisation. The yield of biodiesel produced was determined using Equation (3).

$$
B D \text { yield }(\%)=\frac{\text { Mass of FAME obtained }}{\text { Mass of oil feedstock }}
$$

The quality of both the maggot oil and biodiesel products obtained was determined and assessed according to the EN14214 standard method. The acid value was measured by the titrimetric method of potassium hydroxide solution [27]. The iodine value was determined according to Wij's method [28]; the density and viscosity, both at $40{ }^{\circ} \mathrm{C}$, were determined using an Anton Paar portable density meter (DMA) and a Discovery HR-1 hybrid (DHR) rheometer, respectively. Additionally, the refractive index (n) of the obtained samples was determined using a digital Refractometer (\#PA203 Misco model). The fatty acid profile of the maggot oil feedstock and that of each biodiesel methyl ester produced (FAME) were characterised with a pre-calibrated GC-FID (HP88 GC model equipped with a polar capillary column). 


\section{Conclusions}

This study showed that a pure phase hydroxy sodalite (HS) zeolite could be successfully synthesised from coal fly ash. The mineral phase of good crystallinity and high purity was represented by samples produced over longer hydrothermal synthesis time ( $\geq 48 \mathrm{~h})$. The synthesised samples resulted in various degrees of crystallinity, which exhibited a direct correlation with the hydrothermal synthesis time. Various crystal morphologies evolved with an increase in the synthesis time, including hexagonal cubic crystals associated with high phase HS crystallinity. The high HS crystalline phases were also similar in structural characteristics and major elemental composition, including Si/Al ratio. The biodiesel yield and improved quality directly correlated with crystallinity and increased $\mathrm{Na} / \mathrm{Al}$ ratio. The optimal HS phase with $100 \%$ crystallinity was obtained after a 72 -h hydrothermal synthesis time. This catalyst sample also gave a high biodiesel yield of $84.10 \%$ and acceptable quality that met both the EN and ASTM specifications. This proves the potential of coal fly ash-derived hydroxy sodalite (HS) in biodiesel production and the economic viability of using a waste-derived catalyst and low-cost feedstock. Improved biodiesel yield and quality is envisaged upon further transesterification optimisation studies.

Author Contributions: Conceptualisation and validation, L.P., O.B.; methodology and software, J.M.S.; Formal analysis, O.O.; Writing-Original draft preparation, J.M.S., L.P. and O.O.; writing-review and editing, J.M.S., L.P. and O.O.; supervision, O.B., O.O.; project administration, J.M.S., O.B. and O.O.; Visualisation, L.P. and O.O.

Funding: The authors would like to acknowledge the Environmental NanoScience (ENS) group of the University of Western Cape for providing the required funding for sample analyses.

Acknowledgments: The authors would also like to acknowledge the Department of Chemical Engineering for additional facility to conduct the research at the Cape Peninsula University of Technology (CPUT); Agrifood Station at the Department of Food Technology (CPUT) for GC analysis; The Department of Physics at the University of Western Cape (UWC) and Ithemba Lab for the conduction of SEM and XRD analyses respectively.

Conflicts of Interest: The authors declare no conflict of interest.

\section{References}

1. Weitkamp, J. Zeolites and catalysis. Solid State Ion. 2000, 131, 175-188. [CrossRef]

2. Golbad, S.; Khoshnoud, P.; Abu-Zahra, N. Hydrothermal synthesis of hydroxy sodalite from fly ash for the removal of lead ions from water. Int. J. Environ. Sci. Technol. 2017, 14, 135-142. [CrossRef]

3. Shumba, M.; Chigondo, M.; Guyo, U.; Chigondo, F.; Moyo, M.; Nharingo, T.; Sebata, E. Synthesis of zeolites and their applications in heavy metals removal: A review. Eng. Sci. Technol. 2011.

4. Frising, T.; Leflaive, P. Extraframework cation distributions in $\mathrm{X}$ and $\mathrm{Y}$ faujasite zeolites: A review. Microporous Mesoporous Mater. 2008, 114, 27-63. [CrossRef]

5. Musyoka, N.M.; Missengue, R.; Kusisakana, M.; Petrik, L.F. Conversion of South African clays into high quality zeolites. Appl. Clay Sci. 2014, 97-98, 182-186. [CrossRef]

6. Mezni, M.; Hamzaoui, A.; Hamdi, N.; Srasra, E. Synthesis of zeolites from the low-grade Tunisian natural illite by two different methods. Appl. Clay Sci. 2011, 52, 209-218. [CrossRef]

7. Zielke-Olivier, J.; Vermeulen, D. Fine Ash Leaching in Tailings Dams-An Impact on the Underlying Aquifers? In Proceedings of the IMWA 2016-Mining Meets Water-Conflicts and Solutions, Leipzig, Germany, 11-15 July 2016.

8. Dwivedi, A.; Jain, M.K. Fly ash waste management and overview: A Review. Recent Res. Sci. Technol. 2014, 6, 30-35.

9. Makgaba, C.P.; Daramola, M.O. Transesterification of Waste Cooking Oil to Biodiesel over Calcined Hydroxy Sodalite (HS) Catalyst: A preliminary investigation. In Proceedings of the 2015 International Conference on Sustainable Energy and Environmental Engineering (SEEE 2015), Bangkok, Thailand, 25-26 October 2015.

10. Murayama, N.; Yamamoto, H.; Shibata, J. Mechanism of zeolite synthesis from coal fly ash by alkali hydrothermal reaction. Int. J. Miner. Process. 2002, 64, 1-17. [CrossRef]

11. Querol, X.; Moreno, N.; Umaña, J.t.; Alastuey, A.; Hernández, E.; Lopez-Soler, A.; Plana, F. Synthesis of zeolites from coal fly ash: An overview. Int. J. Coal Geol. 2002, 50, 413-423. [CrossRef] 
12. Leung, D.Y.; Wu, X.; Leung, M.K.H. A review on biodiesel production using catalyzed transesterification. Appl. Energy 2010, 87, 1083-1095. [CrossRef]

13. Lam, M.K.; Lee, K.T.; Mohamed, A.R. Homogeneous, heterogeneous and enzymatic catalysis for transesterification of high free fatty acid oil (waste cooking oil) to biodiesel: A review. Biotechnol. Adv. 2010, 28, 500-518. [CrossRef] [PubMed]

14. Chouhan, A.P.S.; Sarma, A.K. Modern heterogeneous catalysts for biodiesel production: A comprehensive review. Renew. Sustain. Energy Rev. 2011, 15, 4378-4399. [CrossRef]

15. Nabavi, M.S.; Mohammadi, T.; Kazemimoghadam, M. Hydrothermal synthesis of hydroxy sodalite zeolite membrane: Separation of H2/CH4. Ceram. Int. 2014, 40, 5889-5896. [CrossRef]

16. Musyoka, N.M.; Petrik, L.F.; Balfour, G.; Gitari, W.M.; Hums, E. Synthesis of hydroxy sodalite from coal fly ash using waste industrial brine solution. J. Environ. Sci. Health Part A 2011, 46, 1699-1707. [CrossRef]

17. Volli, V.; Purkait, M.K. Selective preparation of zeolite $\mathrm{X}$ and A from flyash and its use as catalyst for biodiesel production. J. Hazard. Mater. 2015, 297, 101-111. [CrossRef]

18. Belviso, C.; Cavalcante, F.; Lettino, A.; Fiore, S. Zeolite Synthesized from Fused Coal Fly Ash at Low Temperature Using Seawater for Crystallization. Coal Combust. Gasif. Prod. 2009, 1, 8-13. [CrossRef]

19. Zhang, X.; Tang, D.; Zhang, M.; Yang, R. Synthesis of NaX zeolite: Influence of crystallization time, temperature and batch molar ratio $\mathrm{SiO}_{2} / \mathrm{Al}_{2} \mathrm{O}_{3}$ on the particulate properties of zeolite crystals. Powder Technol. 2013, 235, 322-328. [CrossRef]

20. Leong, S.Y.; Kutty, S.R.M.; Malakahmad, A.; Tan, C.K. Feasibility study of biodiesel production using lipids of Hermetia illucens larva fed with organic waste. Waste Manag. 2016, 47, 84-90. [CrossRef]

21. Ushakova, N.A.; Brodskii, E.S.; Kovalenko, A.A.; Bastrakov, A.I.; Kozlova, A.A.; Pavlov, D.S. Characteristics of lipid fractions of larvae of the black soldier fly Hermetia illucens. Dokl. Biochem. Biophys. 2016, 468, 209-212. [CrossRef]

22. Li, Q.; Zheng, L.; Cai, H.; Garza, E.; Yu, Z.; Zhou, S. From organic waste to biodiesel: Black soldier fly, Hermetia illucens, makes it feasible. Fuel 2011, 90, 1545-1548. [CrossRef]

23. Nanganoa, L.T.; Mbadcam, K.J.; Kang, S. Synthesis of Hydroxy-sodalite from Fine Fractions of Sandy Clay Loam Soil (Natural Aluminosilicate). Int. J. Chem. Tech. Res. 2016, 9, 725-732.

24. Surendra, K.C.; Olivier, R.; Tomberlin, J.K.; Jha, R.; Khanal, S.K. Bioconversion of organic wastes into biodiesel and animal feed via insect farming. Renew. Energy 2016, 98, 197-202. [CrossRef]

25. Ferreira Madeira, F.; Ben Tayeb, K.; Pinard, L.; Vezin, H.; Maury, S.; Cadran, N. Ethanol transformation into hydrocarbons on ZSM-5 zeolites: Influence of $\mathrm{Si} / \mathrm{Al}$ ratio on catalytic performances and deactivation rate. Study of the radical species role. Appl. Catal. A General 2012, 443-444, 171-180. [CrossRef]

26. Treacy, M.M.; Higgins, J.B. Collection of Simulated XRD Powder Patterns for Zeolites; Fifth (5th) Revised Edition; Elsevier: Amsterdam, The Netherlands, 2007.

27. ResearchGate. How do I determine the Free Fatty Acid (FFA) Percentage in non-edible oils? Available online: https://www.researchgate.net/post/how_do_i_determine_the_Free_Fatty_Acid_FFA_Percentage_ in_non-edible_oils (accessed on 26 February 2019).

28. Japir, A.A.-W.; Salimon, J.; Derawi, D.; Bahadi, M.; Al-Shuja'a, S.; Yusop, M.R. Physicochemical characteristics of high free fatty acid crude palm oil. OCL 2017, 24, D506. [CrossRef]

(C) 2019 by the authors. Licensee MDPI, Basel, Switzerland. This article is an open access article distributed under the terms and conditions of the Creative Commons Attribution (CC BY) license (http://creativecommons.org/licenses/by/4.0/). 